\title{
Antimicrobial Potential of Crude Extract of Curvularia lunata, an Endophytic Fungi Isolated from Cymbopogon caesius
}

\author{
K. S. Avinash, ${ }^{1}$ H. S. Ashwini, ${ }^{1}$ H. N. Ramesh Babu, ${ }^{2}$ and Y. L. Krishnamurthy ${ }^{1}$ \\ ${ }^{1}$ Department of PG Studies and Research in Applied Botany, Kuvempu University, Jnanasahyadri, Shankaraghatta, \\ Karnataka 577451, India \\ ${ }^{2}$ Department of Botany, Sahyadri Science College (Autonomous), Shivamogga, Karnataka 577203, India
}

Correspondence should be addressed to Y. L. Krishnamurthy; murthy_ylk@yahoo.co.in

Received 5 August 2015; Revised 8 November 2015; Accepted 10 November 2015

Academic Editor: Terezinha Inez Estivalet Svidzinski

Copyright (c) 2015 K. S. Avinash et al. This is an open access article distributed under the Creative Commons Attribution License, which permits unrestricted use, distribution, and reproduction in any medium, provided the original work is properly cited.

\begin{abstract}
Cymbopogon caesius grass is an aromatic tall grass species which grows in waste field and along the edges of crop fields in Karnataka. From this grass fungal endophytes were isolated on PDA medium and identified as Curvularia lunata. The fungus was cultured on Potato Dextrose broth for production of fungal metabolites. Ethyl acetate extract of the C. lunata was obtained by liquid-liquid partition of broth of endophyte and evaporation. Dried crude extract was tested for antimicrobial activity by agar well diffusion method. The extract showed antimicrobial nature against all the test pathogens. Crude extract of C. lunata is highly active against Staphylococcus aureus with the inhibition percentage of 92 and Candida albicans with 81 percent inhibition.
\end{abstract}

\section{Introduction}

A number of plant species have been examined, and it is projected that there are more than one million endophytic fungi in association with many plants existing in nature [1]. The success for naturally occurring therapeutic agents depends on fractionation and purification procedures. The plant is an extraordinarily common and widespread source of organic energy. It is thus likely that a huge array of fungi interacts with plants. Plants and fungi engage in intimate relationships that range from harmful to beneficial activities. Parasitic fungi can cause both wild and cultivated plants and sometimes cause serious loss in the agriculture sector. Endophytes are microbes often bacteria or fungi living within a plant at least for part of their life without causing any apparent negative effects. They reside inside the tissues of nearly all the healthy plants. A wide diversity of fungi was isolated from healthy tissues of most terrestrial and aquatic plants and red and brown algae. Fungi are present in most plant parts [2].

Some specific group of endophytic fungi has a close association with grasses. These fungi are transmitted vertically through seed and their impact on the economic value of the host has led to the study of their biology. The grass endophytes, and related fungi, are considered separately from the more common general endophytes. Microorganisms are important sources of active natural products with enormous potential for the discovery of new molecules for drug discovery, industrial use, and agricultural applications [3-7]. Several endophytes were found to produce metabolites that protect plants from insect pests and pathogenic organisms as well as herbivores [8]. There is an ever-growing need for new and useful compounds to provide assistance and relief in all aspects of the human condition [9]. Even though pharmacological industries have produced a number of new antibiotics, resistance to these drugs by microorganisms has increased. Bacteria have the genetic ability to transmit and acquire resistance to drugs, which are utilized as therapeutic agents [10]. Presently fungal endophytes became the major source of bioactives in the therapeutics. More than 38 percent of the biologically active metabolites were from the fungal origin among total active compounds isolated from all the biological sources [11, 12]. Hence the fungal metabolites have increased the interest in the field of study of activities of the extracted molecules. The fungal metabolites were screened for their potential sources as antimicrobial and antitumour agents $[13,14]$. 


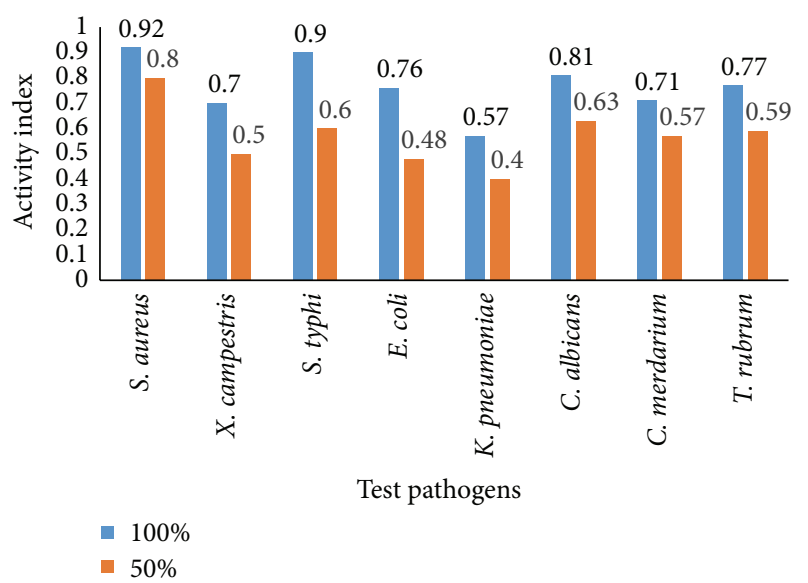

Figure 1: Activity index of EtOAc extract of C. lunata on various pathogens at 100 percent and 50 percent concentration.

Cymbopogon caesius is a common grass growing luxuriantly in dry areas as well as Western Ghats areas of Karnataka, India, which is used for extraction of essential oil for therapeutic purpose. The main objective of this study is to isolate the endophytic fungi from the grass and to evaluate the possibilities of production of fungal metabolites for testing of antimicrobial activity.

\section{Materials and Methods}

2.1. Collection of Plant Samples. Fresh and healthy grass samples were collected from various areas of Hassan district of Karnataka. The plant specimens were brought to laboratory keeping inside the polythene cover to avoid drying of the samples. Processing of the root, stem, and leaf tissues were started by thoroughly rinsing with tap water. Samples were cut into $3-4 \mathrm{~cm}$ pieces prior to rigorous surface sterilization (95\% ethanol for $30 \mathrm{~s}$ and $70 \%$ ethanol for $5 \mathrm{~min}$ followed by $3 \%$ sodium hypochlorite for $25-30 \mathrm{~min}$ ). Surface sterilized tissues were rinsed three times with sterile water, blot dried, cut into small pieces $(1-1.5 \mathrm{~cm})$, and plated on Potato Dextrose Agar (PDA, Hi Media Laboratories, Mumbai, India) plates amended with Amoxillin $\left(250 \mathrm{mgL}^{-1}\right)$ [15]. The efficacy of surface sterilization was confirmed by inoculating the surface sterilized water collected from last wash of the sample in a nutrient medium. The absence of growth of any fungi on the media confirms the efficient surface sterilization of the segments. The inoculated Petri plates were wrapped with Petri seal and incubated at lab temperature. After 3 days of inoculation, the plates were observed daily for growth of the fungi from cultured segments up to one month. The fungus that emerged from tip of the segment was identified on the basis of mycelial morphology and spore characters using fungal manual Hyphomycetes, Taxonomy and Biology [16]. The pure culture of the C. lunata was maintained for the extraction of fungal metabolites.

2.2. Extraction Fungal Metabolites. The mycelia of C. lunata purified on PDA medium and Potato Dextrose broth was

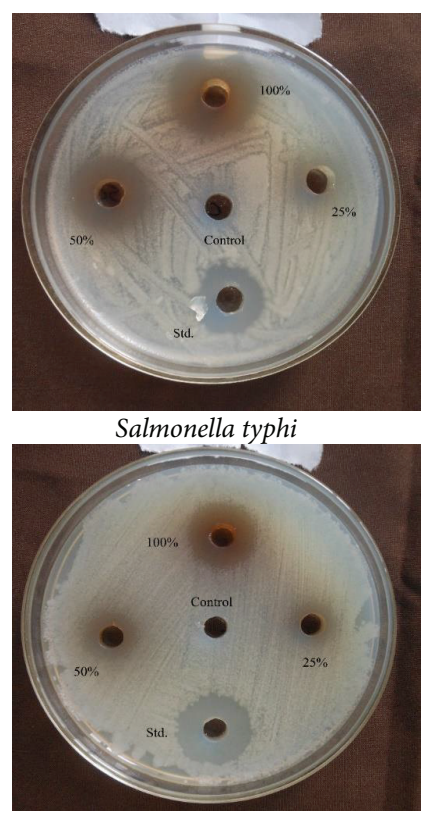

Xanthomonas campestris

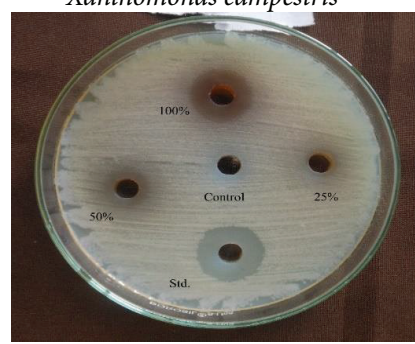

Staphylococcus aureus

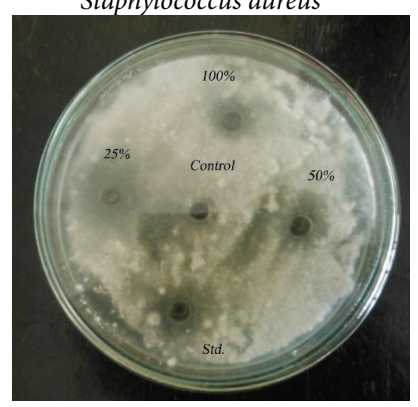

Chrysosporium merdarium

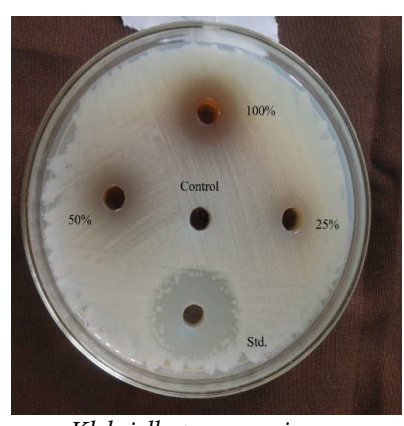

Klebsiella pneumoniae

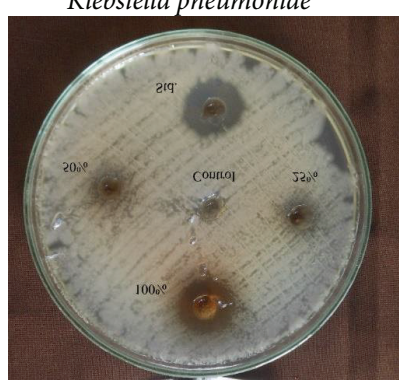

Escherichia coli

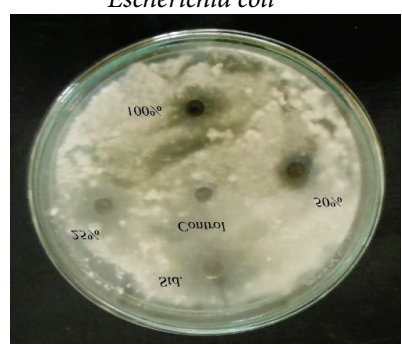

Candida albicans

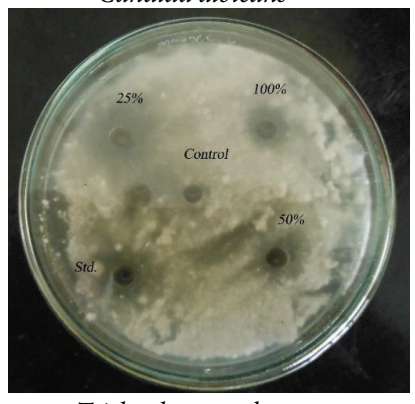

Trichophyton rubrum
FIgURE 2: Antibacterial and antifungal activity of crude extract of $C$. lunata.

used for production of fungal metabolite by fermentation method. The mycelia of $C$. lunata from growing edge was inoculated into $1000 \mathrm{~mL}$ Erlenmeyer flask containing $500 \mathrm{~mL}$ of Potato Dextrose broth medium on a rotary shaker for 1522 days at 25 degrees Celsius. The culture filtrate was filtered through a Whatman filter paper. The filtrate was extracted with the same volume of ethyl acetate twice and the extract was air dried for further analysis.

2.3. Evaluation of Antimicrobial Activity. Test pathogens, namely, Escherichia coli (MTCC 1559), Staphylococcus aureus (MTCC 7443), Xanthomonas campestris (MTCC 2286), Salmonella typhi (MTCC 734), Klebsiella pneumoniae 
TABLE 1: Antimicrobial activity (zone of inhibition, $\mathrm{mm}$ ) on various pathogens by EtOAc extract of C. lunata.

\begin{tabular}{|c|c|c|c|c|c|c|c|}
\hline & \multicolumn{7}{|c|}{ Inhibition zone (mm) } \\
\hline & \multirow[b]{2}{*}{$100 \%^{*}$} & \multicolumn{2}{|c|}{ EtOAc extract } & \multirow{2}{*}{ Standard } & \multicolumn{3}{|c|}{ Activity index (AI) } \\
\hline & & $50 \%$ & $25 \%$ & & $100 \%$ & $50 \%$ & $25 \%$ \\
\hline \multicolumn{8}{|l|}{ Test pathogens } \\
\hline Staphylococcus aureus & $20 \pm 1.5$ & $16 \pm 0.9$ & $12 \pm 0.6$ & 21.6 & 0.92 & 0.8 & 0 \\
\hline Xanthomonas campestris & $14 \pm 1.0$ & $10 \pm 0.5$ & $8 \pm 0.8$ & 20.05 & 0.7 & 0.5 & 0.4 \\
\hline Salmonella typhi & $16 \pm 2.1$ & $11 \pm 0.4$ & 0 & 18.15 & 0.90 & 0.6 & 0 \\
\hline Escherichia coli & $19 \pm 1.5$ & $12 \pm 0.5$ & $8 \pm 0.9$ & 25 & 0.76 & 0.48 & 0.32 \\
\hline Klebsiella pneumoniae & $14 \pm 1.2$ & $10 \pm 1.5$ & 0 & 24.5 & 0.57 & 0.40 & 0 \\
\hline \multicolumn{8}{|l|}{ Fungal pathogens } \\
\hline Candida albicans & $18 \pm 1.2$ & $14 \pm 0.9$ & 0 & 22 & 0.81 & 0.63 & 0 \\
\hline Chrysosporium merdarium & $10 \pm 1.0$ & $8 \pm 0.5$ & 0 & 14 & 0.71 & 0.57 & 0 \\
\hline Trichophyton rubrum & $13 \pm 0.6$ & $10 \pm 0.4$ & 0 & 16.8 & 0.77 & 0.59 & 0 \\
\hline
\end{tabular}

${ }^{*} 1 \mathrm{mg} / \mathrm{mL}$ was taken as $100 \%$.

(MTCC 7028), Candida albicans (MTCC 1637), Chrysosporium merdarium (MTCC 4608), and Trichophyton rubrum (MTCC 3272), were obtained from the culture collections (MTCC). For preparation of inoculum the bacterial cultures were precultured in nutrient broth overnight in an incubator. The fungal inoculum was prepared 5-10-day-old culture grown on Potato Dextrose Agar medium. For antibacterial activity, the test bacteria were spread on the nutrient agar medium in the Petri plates. The $6 \mathrm{~mm}$ wells were made in the medium and the different concentrations $(25 \%, 50 \%$, and $100 \%$ ) of fungal extract along with one standard and one control sample were added to the wells. Amoxillin was used as standard drug whereas DMSO was used as control. After 18 hours of inoculation the inhibition zone was measured. For antifungal activity fluconazole was used as the standard reference drug. The inhibition zone was measured in $\mathrm{mm}$ after 7 days and activity index with respect to standard drug was calculated by using the following formula:

$$
\begin{aligned}
\text { Activity index }= & \frac{\text { Inhibition by extract }(\mathrm{mm})}{\text { Inhibition by standard drug }(\mathrm{mm})} \\
& \times 100 .
\end{aligned}
$$

\section{Results and Discussion}

The results in our study showed the extract of the endophytic fungi $C$. lunata has a good antibacterial activity. The antimicrobial activity of ethyl acetate extract of C. lunata was investigated by well diffusion method against selected pathogens such as S. aureus, E. coli, K. pneumonia, S. typhi, and $X$. campestris. These pathogens have also been tested for commercial antibiotic Amoxillin and results were indicated in Figure 1. The C. lunata metabolite showed varied activity against different pathogens (Figure 2).

S. aureus showed highest activity index of about 0.92 with good inhibition zone of 92 percent at 100 percent concentration of $C$. lunata extract followed by $S$. typhi with the activity index of 0.9. Among five bacterial pathogens taken for the study K. pneumoniae showed the lower activity against the ethyl acetate extract of $C$. lunata. In case of fungal pathogens $C$. albicans showed the highest activity (0.81) followed by T. rubrum (0.77). The extract was less active against fungal pathogens when compared to bacterial pathogens in vitro. At 50 percent concentration of the extract S. aureus showed good activity with the activity index of 0.8 followed by $S$. typhi (0.6) and in case of fungal pathogens $C$. albicans showed highest activity (Table 1 ).

Endophytic fungi have been recognized as a repository of novel secondary metabolites, possessing beneficial biological activities $[17,18]$. Many investigations were carried out to discover the antimicrobial activity of fungal extracts. Endophytic fungus Nodulisporium sp. PT11 isolated from the leaves of Mitragyna javanica exhibited the strongest antimicrobial activity against all test microorganisms (Bacillus subtilis ATCC, 6633, Staphylococcus aureus ATCC 25923, Pseudomonas aeruginosa ATCC 9027, Escherichia coli ATCC 25922, Saccharomyces cerevisiae TISTR 5169, and Candida albicans ATCC 1023) [19], whereas in our study also ethyl acetate extract of the endophytic fungus $C$. lunata showed good activity against all the test pathogens used in the study.

The antimicrobial activity of fungal endophytes isolated from the plant Piper crocatum was tested against various test pathogens like B. subtilis, E. coli, and S. aureus and showed inhibition at $31.25,125$, and $250 \mu \mathrm{g}$ concentration of extract [20]; similarly in our study also S. aureus showed positive result. Ethyl acetate extract exhibited significant result when compared to the hexane and methanol extracts where they showed moderate activity [21, 22]. Endophytic fungi from seagrasses such as Enhalus acoroides could therefore be a good source for obtaining antimicrobial natural products [23] like endophytic fungi from Cymbopogon grass such as $C$. lunata which could be a potent source of antimicrobial natural products. In this study screening of endophytic fungus $C$. lunata revealed the potency of the crude extract against the test microorganisms. The compounds in pure form may be used as antibacterial and antifungal agents. Endophytic fungi may be a vast source of metabolites, which can be used in treatment of various microbial infections and also provide research area for further investigation. Efficient strategies 
should be made to enhance the production of secondary metabolites and further studies are required to identify and characterize the metabolites from endophytic fungi.

\section{Conflict of Interests}

The authors declare that there is no conflict of interests regarding the publication of this paper.

\section{Acknowledgments}

The authors are thankful to the Department of Biotechnology, Government of India, New Delhi, for financial assistance through its grant F. no. BT/PR/14396/NDB/52/179/2010 and Kuvempu University for administrative and laboratory support. They were also thankful to Mr. Shravana Kumar S and Mr. Srinivas SG for their help in the collection of environmental samples from the field.

\section{References}

[1] A. Sen and A. Batra, "Evaluation of antimicrobial activity of different solvent extracts of medicinal plant: Melia azedarach L," International Journal of Current Pharmaceutical Research, vol. 4, no. 2, pp. 67-74, 2012.

[2] G. C. Carroll and F. E. Carroll, "Studies on the incidence of coniferous needle endophytes in the Pacific Northwest," Canadian Journal of Botany, vol. 56, no. 24, pp. 3034-3043, 1978.

[3] A. L. Demain, "Pharmaceutically active secondary metabolites of microorganisms," Applied Microbiology and Biotechnology, vol. 52, no. 4, pp. 455-463, 1999.

[4] N. P. Keller, G. Turner, and J. W. Bennett, "Fungal secondary metabolism-from biochemistry to genomic," Nature Reviews Microbiology, vol. 3, no. 12, pp. 937-947, 2005.

[5] G. Strobel, "Harnessing endophytes for industrial microbiology," Current Opinion in Microbiology, vol. 9, no. 3, pp. 240-244, 2006.

[6] A. Porras-Alfaro and P. Bayman, "Hidden fungi, emergent properties: endophytes and microbiomes," Annual Review of Phytopathology, vol. 49, pp. 291-315, 2011.

[7] M. Qadri, S. Johri, B. A. Shah et al., "Identification and bioactive potential of endophytic fungi isolated from selected plants of the Western Himalayas," SpringerPlus, vol. 2, no. 1, pp. 1-14, 2013.

[8] K. Saikkonen, P. Wäli, M. Helander, and S. H. Faeth, "Evolution of endophyte-plant symbioses," Trends in Plant Science, vol. 9, no. 6, pp. 275-280, 2004.

[9] N. Sadrati, H. Daoud, A. Zerroug, S. Dahamna, and S. Bouharati, "Screening of antimicrobial and antioxidant secondary metabolites from endophytic fungi isolated from wheat (Triticum durum)," Journal of Plant Protection Research, vol. 53, no. 2, pp. 129-136, 2013.

[10] G. G. F. Nascimento, J. Locatelli, P. C. Freitas, and G. L. Silva, "Antibacterial activity of plant extracts and phytochemicals on antibiotic resistant bacteria," Brazilian Journal of Microbiology, vol. 31, no. 4, pp. 247-256, 2000.

[11] J. Bérdy, "Bioactive microbial metabolites-a personal view," Journal of Antibiotics, vol. 58, no. 1, pp. 1-26, 2005.

[12] S. J. Higginbotham, A. E. Arnold, A. Ibañez, C. Spadafora, P. D. Coley, and T. A. Kursar, "Bioactivity of fungal endophytes as a function of endophyte taxonomy and the taxonomy and distribution of their host plants," PLoS ONE, vol. 8, no. 9, Article ID e73192, 2013.

[13] H. J. D. Dorman and S. G. Deans, "Antimicrobial agents from plant: antibacterial activity of plant volatile oils," Journal of Applied Microbiology, vol. 88, no. 2, pp. 308-316, 2000.

[14] B. Tepe, D. Daferera, M. Sökmen, M. Polissiou, and A. Sökmen, "In vitro antimicrobial and antioxidant activities of the essential oils and various extracts of Thymus eigii M. Zohary et P.H. Davis," Journal of Agricultural and Food Chemistry, vol. 52, no. 5, pp. 1132-1137, 2004.

[15] S. R. Ghimire, N. D. Charlton, J. D. Bell, Y. L. Krishnamurthy, and K. D. Craven, "Biodiversity of fungal endophyte communities inhabiting switchgrass (Panicum virgatum L.) growing in the native tallgrass prairie of northern Oklahoma," Fungal Diversity, vol. 47, pp. 19-27, 2011.

[16] C. V. Subramanian, Hyphomycetes, Taxonomy and Biology, Academic Press, New York, NY, USA, 1983.

[17] G. F. Bills and J. D. Polishook, "Microfungi from Carpinus caroliniana," Canadian Journal of Botany, vol. 69, no. 7, pp. 14771482, 1991.

[18] G. A. Strobel, "Microbial gifts from rain forests," Canadian Journal of Plant Pathology, vol. 24, no. 1, pp. 14-20, 2002.

[19] T. Pharamat, T. Palaga, J. Piapukiew, A. J. S. Whalley, and P. Sihanonth, "Antimicrobial and anticancer activities of endophytic fungi from Mitrajyna javanica Koord and Val," African Journal of Microbiology Research, vol. 7, no. 49, pp. 5565-5572, 2013.

[20] P. Astuti, Wahyono, and O. A. Nababan, "Antimicrobial and cytotoxic activities of endophytic fungi isolated from Piper crocatum Ruiz \& Pav," Asian Pacific Journal of Tropical Biomedicine, vol. 4, supplement 2, pp. S592-S596, 2014.

[21] M. G. Desale and M. G. Bodhankar, "Antimicrobial activity of endophytic fungi isolated from Vitex negundo linn," International Journal of Current Microbiology and Applied Sciences, vol. 2, no. 120, pp. 389-395, 2013.

[22] J. Lou, L. Fu, R. Luo, X. Wang, H. Luo, and L. Zhou, "Endophytic fungi from medicinal herb Salvia miltiorrhiza Bunge and their antimicrobial activity," African Journal of Microbiology Research, vol. 7, no. 47, pp. 5343-5349, 2013.

[23] P. Supaphon, S. Phongpaichit, V. Rukachaisirikul, and J. Sakayaroj, "Diversity and antimicrobial activity of endophytic fungi isolated from the seagrass Enhalus acoroides," Indian Journal of Geo-Marine Sciences, vol. 43, no. 5, pp. 785-797, 2014. 

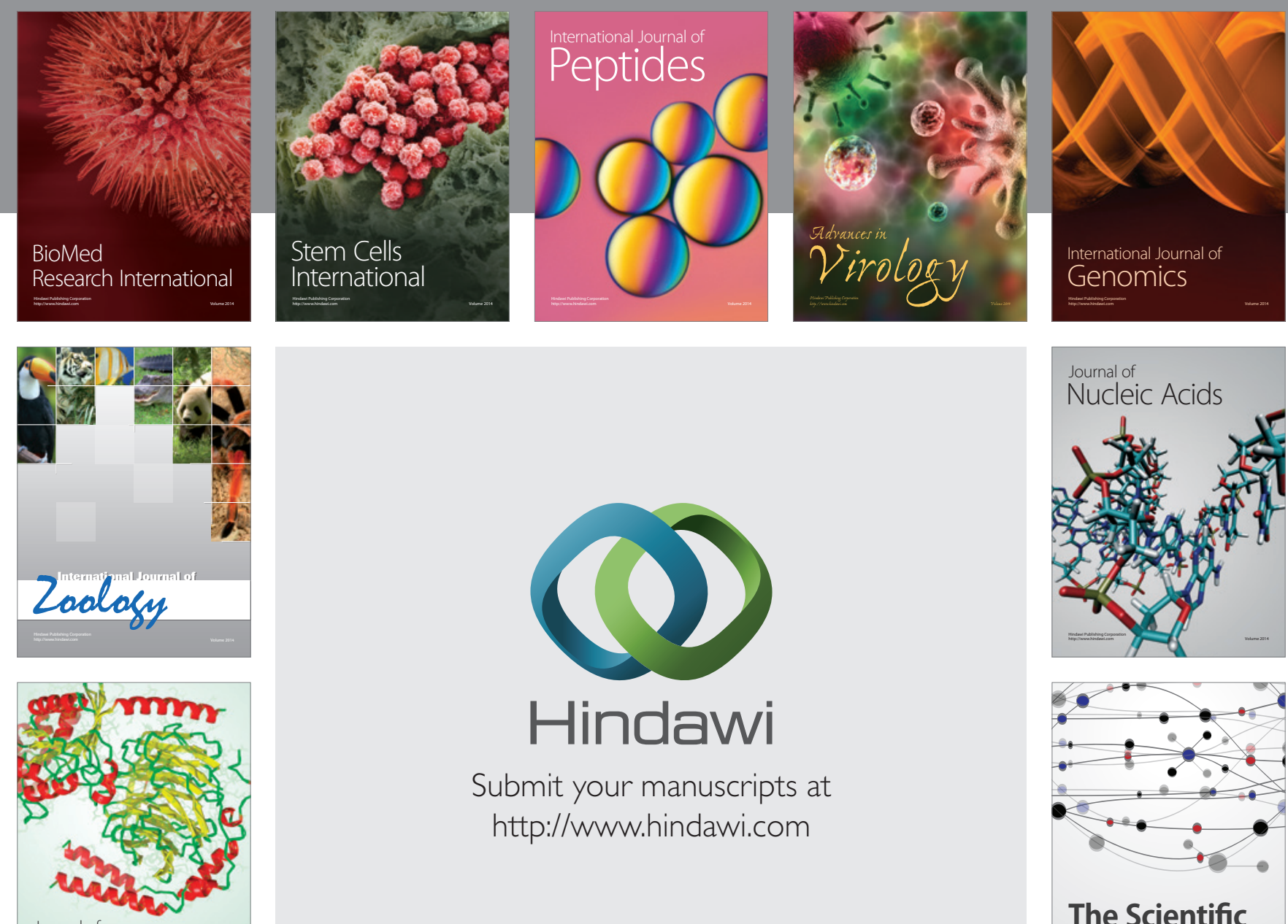

Submit your manuscripts at

http://www.hindawi.com

Journal of
Signal Transduction
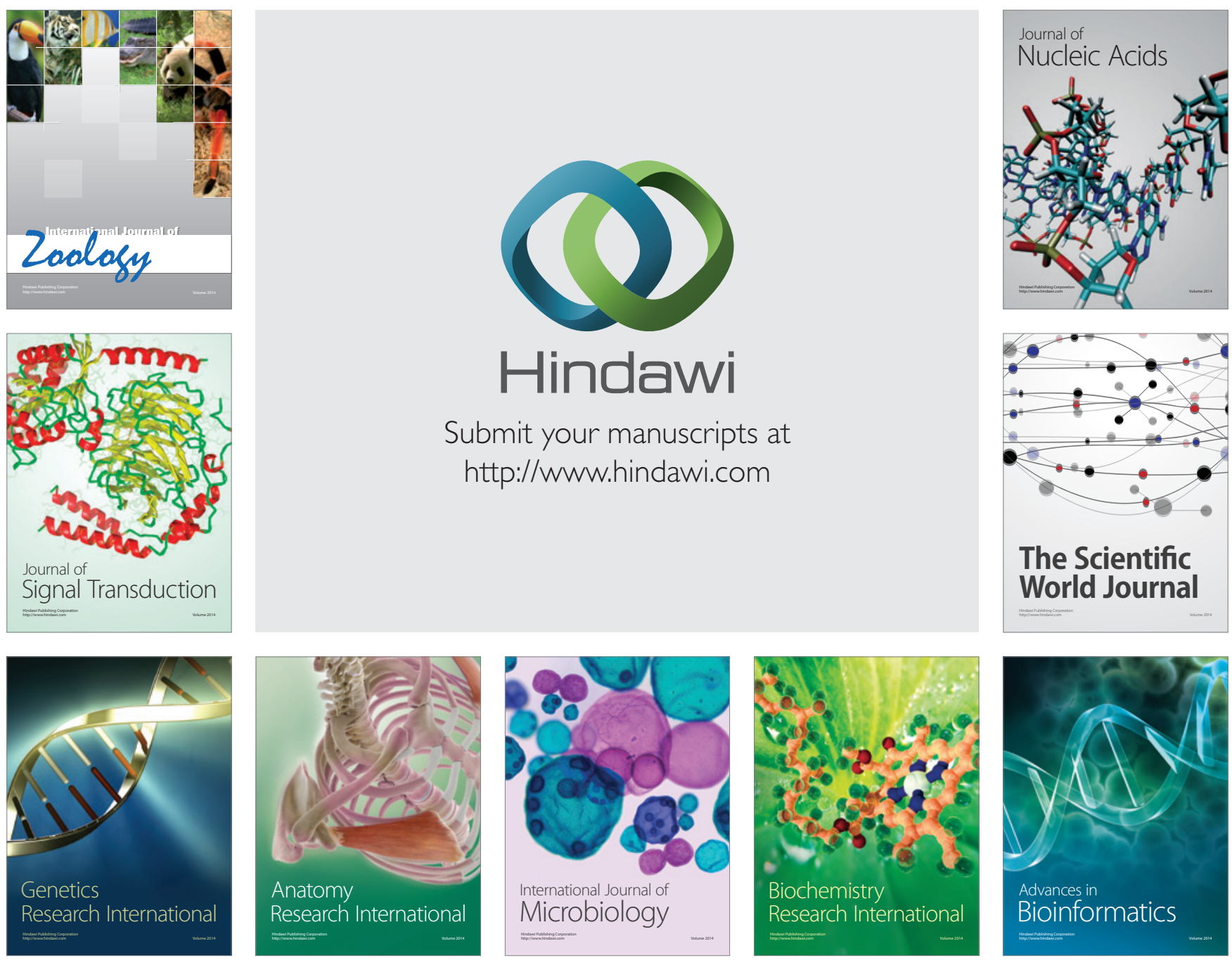

The Scientific World Journal
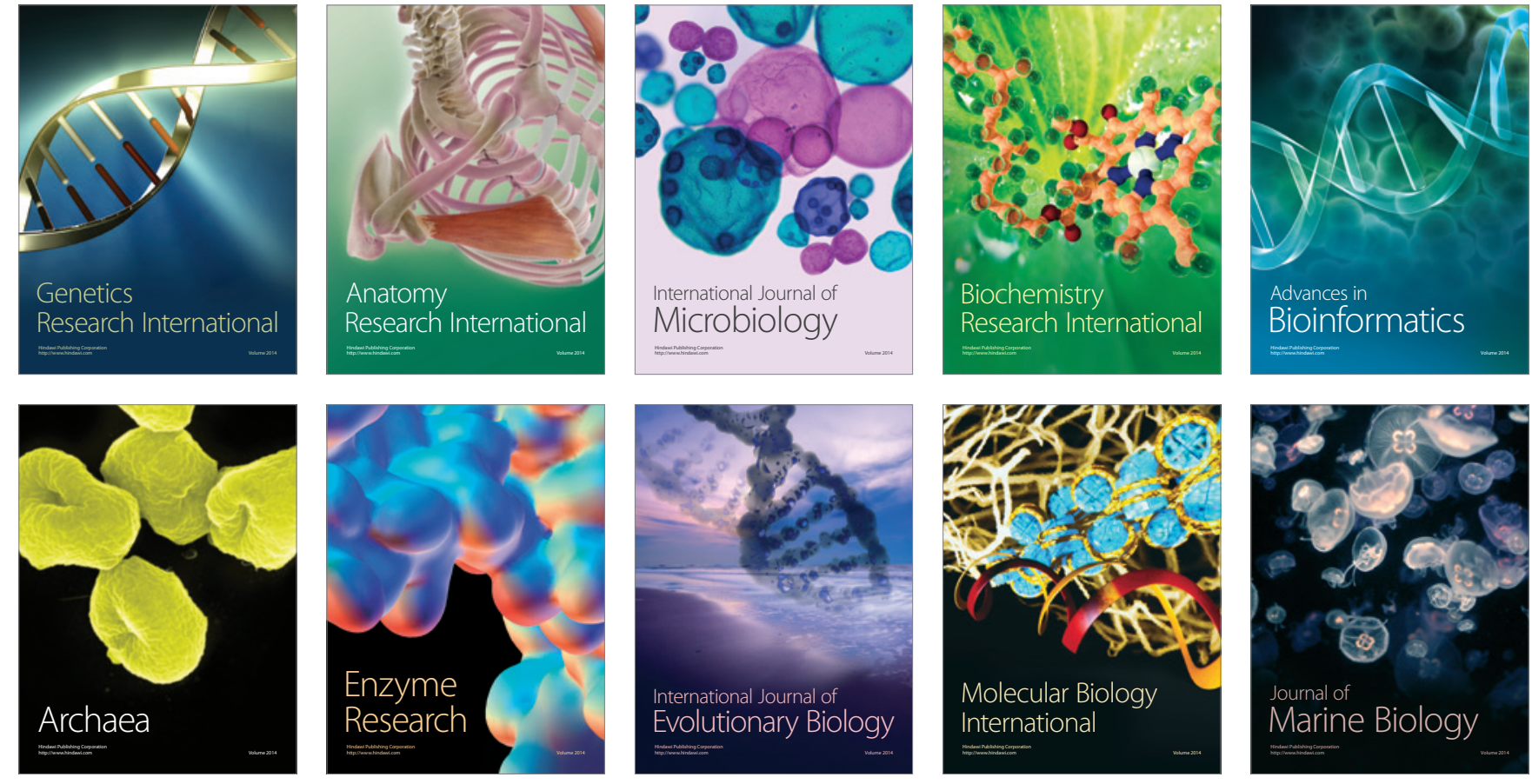